\title{
OCCUPATIONAL RISK ASSESSMENT IN RMG, TEXTILE AND SHIP BREAKING INDUSTRIES OF BANGLADESH
}

\author{
Jannatul Ferdous ${ }^{1}$, Sharmin Jahan Mim ${ }^{1}$, Md Mizanur Rahman Jony ${ }^{2}$ and \\ Sultana Razia Syeda ${ }^{1^{*}}$ \\ ${ }^{1}$ Department of Chemical Engineering, Bangladesh University of Engineering and Technology, \\ Dhaka 1000, Bangladesh \\ ${ }^{2}$ Department of Inspection for Factories and Establishments (DIFE), Ministry of Labour and \\ Employment, Government of the People's Republic of Bangladesh
}

\begin{abstract}
In this study occupational risk assessment in Readymade Garments (RMG), Textile and Ship Breaking Industries of Bangladesh was carried out utilizing accident database of Department of Inspection for Factories and Establishments (DIFE), Ministry of Labour and Employment. The study focused on the workplace incidents reported to DIFE from 2016-2018 in RMG, Textile and Ship Breaking industries of Bangladesh. The risk analysis was conducted based on severity and likelihood of events, the latter comprising: frequency of exposure to the hazard, duration of exposure to the hazard, probability of occurrence of a hazardous event, and technical and human possibility of avoiding or limiting the harm. To carry out the assessment, survey data including working time, accident frequency, cause of accident, nature of injury, use of personal protective equipment (PPE), health safety policy, first aid facility etc. were collected from DIFE. The risk scores and economic losses due to accidents in different years for each industry were estimated. The overall risk scores estimated for RMG and Textile industry were found to be higher than that for Ship Breaking industry. However, in Ship Breaking industry $41.3 \%$ of total incidents are of very high-risk, which is much higher than the percentage of such incidents in RMG or Textile industry. It was also found that the total compensation provided to the workers as reported to DIFE is $58.5 \%$ less of the estimated cost based on the fatality and type of injuries.
\end{abstract}

Keywords: Occupational risk assessment, Readymade Garments (RMG), Textile, Ship Breaking

\section{Introduction}

International statistics indicates that implementation of occupational safety and health has always been challenging all over the world [1]. According to International Labour Organization (ILO), the work-related fatal injuries and diseases have increased from 2.3 million to 2.78 million per year, increasing the global cost of the failure to adequately address occupational safety and health concerns to an estimated $3.94 \%$ of global GDP per year [1]. ILO further emphasizes that managing safe work in enterprises is an investment to the work force that leads to improvements in productivity.

In developing countries like Bangladesh, undergoing rapid industrialization, the importance of $\mathrm{OSH}$ is increasingly realized. However, no organizations like OSHA or agencies have been developed that could act as a referral center for different standards or occupational permissible limits. A system of good practices of occupational safety and health is an essential element of social and economic development goals.
A proper health and safety management relies on risk control, which is underpinned by the process of an effective risk assessment [2]. An occupational risk assessment is a systematic procedure to identify potential health hazards, evaluate the extent of exposure, and to establish the need for, and the effectiveness of control measures [3].

This research involves an attempt for occupational risk assessment in Readymade Garments (RMG), Textile and Ship Breaking industries using a semi-quantitative tool based on the accidents happened in the workplace. The survey data regarding accidents occurred in these industries was collected from Department of Inspection for Factories and Establishments (DIFE), Ministry of Labour and Employment, Government of the People's Republic of Bangladesh. These data were processed and further analysed using a tool which is adapted from afrooz et al, 2014 [4]. Again, the economic losses in these three sectors caused by the incidents reported from 2016 to 2018 were also estimated in this study. 


\subsection{Problem Statement}

RMG, Textile and Ship Breaking industries of Bangladesh has expanded dramatically over the last three decades as along with increased concerns over occupational health and safety in these sectors. Taking the advantages of workers' poverty and ignorance, the owners force the workers to work in unsafe and unhealthy workplace [5]. In Bangladesh it is estimated that 11.7 thousand workers suffer from fatal accidents and a further 24.5 thousand die from work related diseases across all sectors each year which lead the victims spend an average of US \$4 on each injury [6]. Since RMG is a highly labourintensive industry, the sector is also the largest industrial employer in the country with around 6.3 million working people in these factories [7]. Textile sector is also one of the vital industrial sectors as it contributes to $13 \%$ of GDP and $81 \%$ of the export earnings comes from Textile and related industries [8]. Ship Breaking is one of the important sectors in Bangladesh and it is estimated worth an annual turnover of around 1.5 billion dollars [9]. The Ship Breaking industry in Bangladesh has been strongly criticized by global NGOs for many years because of its unsafe working environments. So, it has become a prime concern to ensure and maintain a safe and sound working atmosphere for workers in these sectors.

\subsection{Research Objective}

The objective of this study is to-

1. assess the existing situation of occupational safety and health associated with RMG, Textile and Ship Breaking sectors in Bangladesh.

2. investigate various hazardous incidents and their risk scores in these three industrial sectors using a semi-quantitative risk estimation tool based on the data obtained from DIFE.

3. analyse the economic losses due to the accidents occurred in RMG, Textile and Ship Breaking sectors.

\section{Methodology}

A methodology adopted for this work is presented in the form of a flow chart in Fig. 1. In the primary stage of our work, the survey data of RMG, Textile and Ship Breaking sectors from 2016 to 2018 were collected from DIFE regarding number and cause of accidents, nature of injury, use of personal protective equipment's (PPE), health safety policy etc in various industries.

From the survey data, several scenarios came out from which the hazardous events were identified. Based on the occurrence of hazardous events, risk assessment was carried out in these three sectors of Bangladesh. Once a hazard has been identified, the likelihood and possible severity of injury or harm were assessed. The occupational risk estimation tool in terms of the number of risk parameter levels and definitions, proposed by Afrooz' was applied to assess the risk of different hazardous situations from the likelihood and possible severity of injury and the risk scores were calculated for respective scenarios [4].

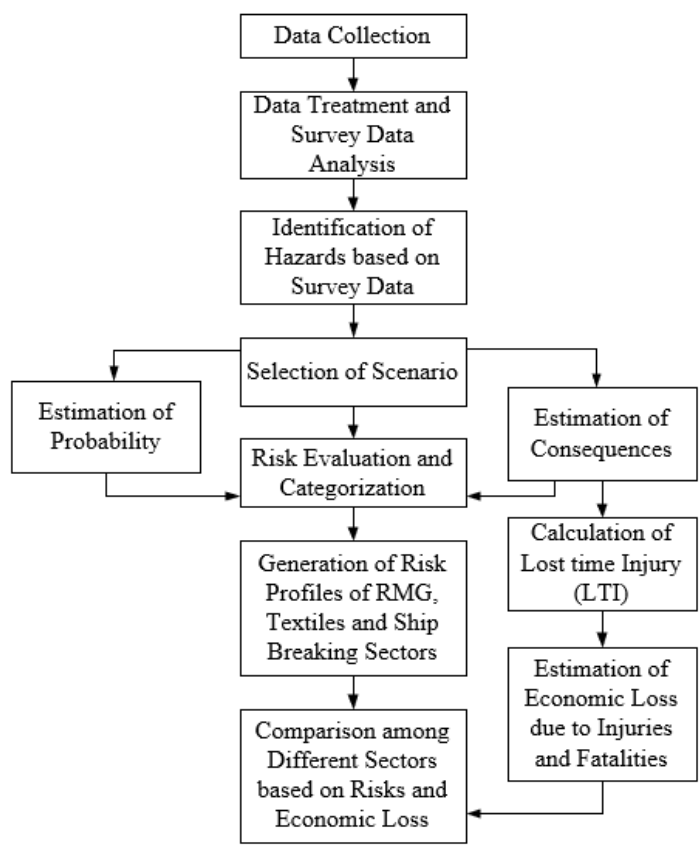

Fig. 1: Flow diagram of the analysis conducted in this research

Lost time injury (LTI), an indicator of safety performance, was estimated based on the days away from work of an injured worker. The direct costs for the same incidents were also estimated using LTI.

\subsection{Risk Assessment Tool and Its Parameters and Levels}

A semi-quantitative rating system was used in which values were assigned to the levels of each risk parameter. The tool selected for the estimation of risks of the accidents occurred in RMG, Textile and Ship Breaking sectors, according to the recorded data, was adapted from afrooz et al 2014 [4].

The equation was used as follows:

Risk Value $(\mathrm{R})=$ Severity of harm $(\mathrm{S}) \times$ Probability of occurrence of harm $(\mathrm{Ph})$

Probability of occurrence of harm $(\mathrm{Ph})=$ Frequency of exposure to the hazard (Exf) + Duration of exposure to the hazard (Exd) $+2 \times$ Probability of occurrence of hazardous event $(\mathrm{Pe})+$ Possibility of avoidance (A)

Here, the risk value was calculated from the multiplication of Severity $(\mathrm{S})$ and Probability $(\mathrm{Ph})$ for each occurrence. The numerical value of $\mathrm{Ph}$ was calculated by using four parameters: Exf, Exd, Pe and A. Here, the weight for the Pe value is twice that of the other parameters. This is because the likelihood of occurrence of a hazardous event, which may be of a technical nature or caused by a person, has a higher 
rank than the other parameters. The possibility of avoidance, A is included in this tool because it is believed that estimating residual risk after the implementation of safety measures is more realistic. As the risk parameters of the selected tool were qualitatively scaled, the following rating system was used to transform the parameters into quantitative measures by which quantitative values were assigned to the levels of each risk parameter [4]. These values are based on a numerical rating scale of $1-5$, where 1 is the lowest risk and 5 is the highest. These parameters, their corresponding risk levels and the quantitative values are presented in Table 1.

Table 1

Parameters and corresponding risk rank

\begin{tabular}{|c|c|c|c|c|c|}
\hline Severity of harm (S) & $\begin{array}{l}\text { Frequency of } \\
\text { exposure to the } \\
\text { hazard (Exf) }\end{array}$ & $\begin{array}{l}\text { Duration of } \\
\text { exposure to the } \\
\text { hazard (Exd) }\end{array}$ & $\begin{array}{c}\text { Probability of } \\
\text { occurrence of a } \\
\text { hazardous event }(\mathrm{Pe})\end{array}$ & $\begin{array}{l}\text { Technical \& human } \\
\text { possibility of } \\
\text { avoiding/limiting } \\
\text { harm (A) }\end{array}$ & Rank \\
\hline $\begin{array}{l}\text { Slight injuries requiring no first aid } \\
\text { or injuries requiring first aid but } \\
\text { without lost time }\end{array}$ & $\begin{array}{l}\text { Less than once per } \\
\text { year }\end{array}$ & $\begin{array}{l}<1 / 20 \text { of work } \\
\text { time }\end{array}$ & Negligible & Highly significant & 1 \\
\hline $\begin{array}{l}\text { Injuries requiring more than first } \\
\text { aid and with lost time or when there } \\
\text { is irreversible harm and slight } \\
\text { disability, but the employee can } \\
\text { return to the same job }\end{array}$ & Annually & $\begin{array}{l}1 / 10 \text { of work } \\
\text { time ( } 45 \text { min } \\
\text { per } 8 \text {-hour shift })\end{array}$ & Unlikely & Significant & 2 \\
\hline $\begin{array}{l}\text { Serious disability, the employee } \\
\text { being able to return to work, but } \\
\text { perhaps not to the same job }\end{array}$ & Monthly & $\begin{array}{c}1 / 5 \text { of work } \\
\text { time }(90 \text { min } \\
\text { per } 8 \text {-hour shift })\end{array}$ & Possible & $\begin{array}{l}\text { Somewhat likely, } \\
\text { with some conditions }\end{array}$ & 3 \\
\hline $\begin{array}{l}\text { Permanent disability or the } \\
\text { employee can no longer work }\end{array}$ & Weekly & $\begin{array}{l}\text { Half of work } \\
\text { time } \\
\text { (4 h per } 8 \text {-hour } \\
\text { shift) }\end{array}$ & Likely & Unlikely & 4 \\
\hline One or more deaths & $\begin{array}{c}\text { Daily to } \\
\text { continuously } \\
\text { (several times per } \\
\text { hour) }\end{array}$ & $\begin{array}{l}\text { Continuously } \\
\text { during work } \\
\text { time }\end{array}$ & Significant & Nil & 5 \\
\hline
\end{tabular}

\subsection{Categorization of Risk Scores}

In this study, a set of values was applied to each parameter to determine a rating of individual factor and then the overall risk score was calculated. Thus, the total risk score for each hazardous scenario follows a grade and this grade defines risk category for an incident [4]. The risk scores obtained from the risk estimation process for the incidents occurred in RMG, Textile and Ship Breaking sectors have been graded from high to low-risk scores and vary mostly from 10 to 90 . The risk categories with corresponding actions for risk mitigation are presented below in Table 2.

Table 2

Risk categorization and required actions for different risk scores

\begin{tabular}{lll}
\hline $\begin{array}{c}\text { Risk } \\
\text { Score }\end{array}$ & $\begin{array}{c}\text { Risk } \\
\text { Category }\end{array}$ & \multicolumn{1}{c}{ Actions } \\
\hline$>90$ & Very High & $\begin{array}{l}\text { Immediate action is needed and access to } \\
\text { the hazard should be restricted until the } \\
\text { risk can be lowered to an acceptable level }\end{array}$ \\
\hline $90-71$ & High & $\begin{array}{l}\text { Action is needed quickly (within 1-2 days) } \\
\text { and the task should not proceed unless the } \\
\text { risk is assessed and controlled }\end{array}$ \\
\hline $70-31$ & Extensive & $\begin{array}{l}\text { Action is required within a week to } \\
\text { eliminate or minimise the risk }\end{array}$ \\
\hline $30-10$ & Potential & $\begin{array}{l}\text { Necessary action is required within a } \\
\text { reasonable timeframe (2-4 weeks) to } \\
\text { eliminate or minimise the risk }\end{array}$ \\
\hline $10-0$ & Readily & $\begin{array}{l}\text { To be eliminated or lowered when } \\
\text { possible }\end{array}$ \\
\hline
\end{tabular}

\subsection{Economic Loss Estimation}

In this work, LTI was calculated by analysing the survey data to consider the direct costs associated with occupational injuries and fatalities in RMG, Textile and Ship Breaking sectors of Bangladesh according to the data from 2016 to 2018. The economic loss calculated in this research includes the compensation provided to an injured or dead worker according to Bangladesh Labour Act, 2006 [10]. The amount of loss was estimated based on the severity of accidents occurred and consequent days away from work.

\section{Data Source and Data Treatment}

\subsection{Data Source}

The primary data were gathered through a survey report from Department of Inspection for Factories and Establishments (DIFE) where they engaged in conducting inspections on factories and establishments. DIFE has an overall scope of inspecting 8.3 million economic units [11]. Due to manpower shortages and priorities based on economic importance, DIFE focuses on inspecting RMG, Textile and other big industries which are institutionalized. Their inspections cover building assessment (structural integrity, fire and electrical safety), recording number and causes of injury and 
fatalities, inspecting safety practices and workers' institutional rights and the enforcement of Labour Laws in Bangladesh [12].

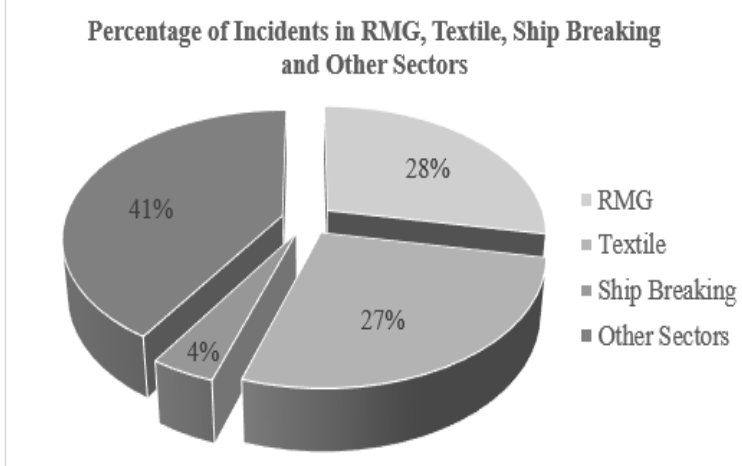

Fig. 2: Percentage of incidents in the RMG, Textile, Ship Breaking and other industrial sectors as per the data collected from DIFE [12]

Survey data from DIFE covered the area of the factories, number of casualties and most importantly different causes of injuries which helped to identify the hazardous situation prevailing there. It also listed the compensation amount distributed among the victims and the victims' families.

Fig. 2 shows the variation on documented data of different sectors. About $28 \%$ and $27 \%$ of the total survey data were documented in RMG and Textile sectors. For the Ship Breaking industry, only $4 \%$ of total survey data were reported for the threeconsecutive years. Other sectors occupied $41 \%$ of survey data. The recorded data consisted around 298, 192 and 38 factories in RMG, Textile and Ship Breaking sectors, respectively.

\subsection{Data Treatment}

\subsubsection{RMG and Textile}

RMG industries convert the finished textile product received from clothing factories to wearable clothes and garments, whereas the textile industry is mainly concerned with the design, production and distribution of yarn, cloth and clothing. RMG sector has become one of the fastest growing sectors in the Bangladeshi economy. These two sectors are very much dependable on one another.

\subsubsection{Category of Hazard}

Hazard is classified based on the nature of occurrences. In the textile sector spinning, knitting and dyeing mills were included whereas readymade garments, embroidered boutique factories were included in the RMG sector. Generally, needle cut, cut in the cutter machine, scissor cut, and slight cut were found to be in significant numbers in knitting and spinning mills in the textile sector. Carelessness of workers during work also enhanced the number of occurrences. The number of occurrences due to Fire hazard were high in comparison to the other hazard categories.

\subsubsection{Different Incidents vs Category of Hazards of RMG and Textile}

The survey reports from DIFE during 2016, 2017, and 2018 were used to categorize the data into different hazard types. It helped to distinguish various incidents happened in the corresponding years and to draw a trend of those incidents.

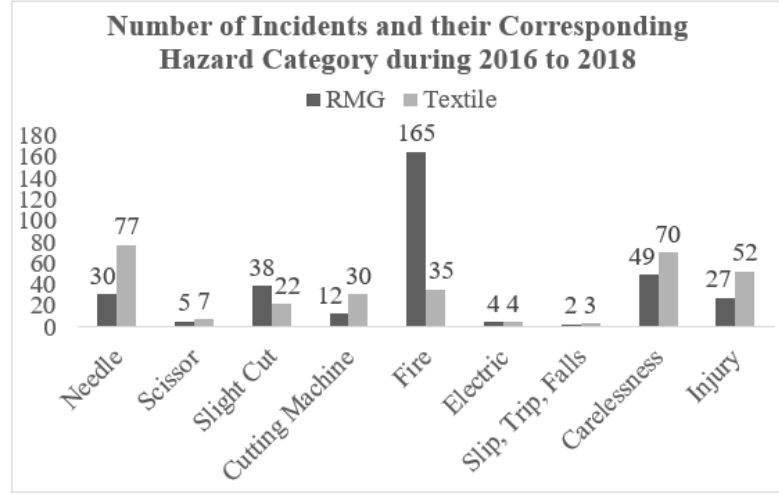

Fig. 3: Number of incidents occurred vs category of hazard in RMG and Textile sectors during 2016, 2017 and 2018

In this Fig. 3, each column depicts the number of occurrences for corresponding hazard types in RMG and Textile sectors. The majority of incidents were caused due to fire hazard category and the rate was very high for RMG sectors.

\subsubsection{Ship Breaking Industry and Corresponding Hazards}

Ship Breaking is a challenging process due to the structural complexity of ships with many environmental, safety and health issues. The Ship Breaking industry has gained a lot of attention because of the revenue earned from it as well as many fatal accidents causing serious disability and human deaths.

It is an admitted fact that ships are embedded with hazardous elements such as asbestos, PCB, TBT, Lead and other heavy metals which pose serious threat to people's health. Safety of the workers who are deployed in Ship Breaking industries are put on stake. During beaching of ships to the shore, hazardous incidents, such as impacts are more likely to occur. Due to messy floor space workers are exposed to slip and trip hazards while working in the high altitude from the ground, workers are exposed to fall hazards. The leftover chemicals and fuel after abandoning the ship are susceptible to chemical and fire hazard during welding and cutting of the ship [13]. 
Ship Breaking is an inherently hazardous operation. The hazards found in the documented 38 factories are categorized below.

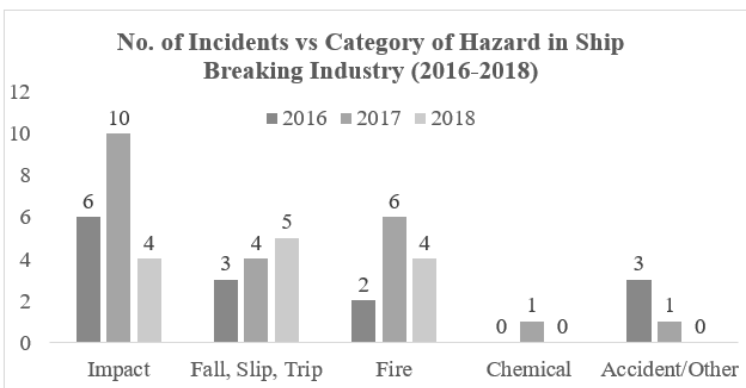

Fig. 4: Number of incidents occurred for different category of hazard in Shipbreaking industry for three consecutive years

In Fig. 4, it is noticeable that impact hazard was the most dominant hazard category in Ship Breaking industry among all other category of hazards workers can be exposed to. Falling of high metal objects caused the highest number of occurrences of impact hazard. The second-best occurrences were due to fall, slip and trip hazard and fire hazard. While workers onboard fall, slip and trip occurs because of slippery or uneven surfaces.

\subsection{Risk Assessment Procedure for Different Industrial Sectors}

Risk calculation was done by using risk estimation tool and more than 600 incidents in RMG and Textile sectors and about 50 occurrences in the Ship Breaking industry for the corresponding three years were considered to assess the risk. The selected risk estimation tool to calculate risk score includes all the risk parameters highlighted in ISO 12100 [14].

As per the risk estimation tool, a sample calculation is presented in the following section based on the various identified hazardous scenarios that are considered in section 3.2.3. In this example, slip, trip or falls in the walk area have been considered to be potential to cause injury or damage to head or other body parts of the injured. Here, the activity might involve workers or supervisors to walk past the machines and the hazard could be the slippery or uneven surface. Hazardous situation can be expressed as slip on the wet floor or trip on the obstruction of the floor and situation can get worse if fall on a rotating or reciprocating part of a machine occurs. Thereby, parameters for the equation presented in section 2.1 are denoted as,

Severity of harm (S): Injuries requiring more than first aid and with lost time, therefore, $S=2$

Frequency of Exposure (Exf): Person may fall on a very rare basis and can assume to happen once in a year, therefore, $\operatorname{Exf}=2$

Duration of Exposure (Exd): Person's duration of walking on the slippery surface varies with the industries, for example if it is a dying factory then there is water all over the production floor but in other industries, the floors may remain dry for almost all the time, therefore, $\operatorname{Exd}=3$

Probability of occurrence of a hazardous event (Pe): Statistical data shows at least 3 hazardous events occurred in a year and training and experience of the injured may be considered as Moderate. Reliability of machine can be considered as moderate (Lacks in spill prevention and control). Unsafe activity of spill and its control is less than adequate and work pressure lead to lose attention while walking on the floor, therefore, $\mathrm{Pe}=3$

Possibility of avoidance (A): If exposed to the hazardous situation of uneven surface or slippery floor there is very high possibility of getting fall if not careful. $\mathrm{A}=4$

Probability of occurrence of harm $(\mathrm{Ph})=$ Frequency of exposure to the hazard (Exf) + Duration of exposure to the hazard (Exd) $+2 \times$ Probability of occurrence of a hazardous event $(\mathrm{Pe})+$ Possibility of avoidance $(A)=E x f+E x d+2 P e+A=2+3+2 \times 3+4=15$

Risk Value $(\mathrm{R})=$ Severity of harm $(\mathrm{S}) \times$ Probability of occurrence of harm $(\mathrm{Ph})=\mathrm{S} \times \mathrm{Ph}=2$ $\times 15=30$, which falls under the potential risk category.

\section{Economic Loss Due to Occupational Incidents}

\subsection{Direct Cost Estimation}

The survey data collected from DIFE, covered the incidents in factories of RMG, Textile and Ship Breaking sectors of Bangladesh from 2016 to 2018 which consisted of occupational injuries, illnesses, and fatalities, along with the costs associated with direct payment of medical and related claims by the law of Bangladesh Labour Act, 2006 [10]. The Lost Time Injury (LTI) for incidents occurred in these sectors from 2016 to 2018 were determined by analysing the type of occurrence.

This study mainly focused on the direct costs associated with occupational claims, in cases of both morbidity and mortality, in terms of medical expenses, rehabilitation costs, funeral compensation costs, and work compensation costs for lost earnings. All costs in taka were converted into US dollar values (US \$) $(\$ 1=80 \mathrm{TK}$, as of 2018).

According to Bangladesh Labour Act, 2006 (Section-151, Schedule-V), if a worker dies then the compensation will be BDT 1,00,000.00 (USD $1,250.00$ ) and if a worker is permanently disabled, then the compensation will be BDT 1,25,000.00 (USD 1,563.00). For a partially disabled worker, compensation depends on the severity of the injury. According to Bangladesh Labour Act, 2006, (Section 151, Schedule-I), for 54 different categories of injuries, the compensation starts from minor disability to severe disability (5\% to $70 \%$ of the compensation for permanent disability) which accounts for BDT $6,250.00$ (USD 78.00) to BDT - 
87,500.00 (USD 1,094.00) [10]. So, the amount of compensation to be provided to the workers for each type of injury or disability and fatality was determined analysing the annual LTI obtained and subsequent direct cost calculated by data for these sectors are shown in Table 3.

Table 3

Annual different lost time injury (LTI) and direct costs based on severity of injury in RMG, Textile and Ship Breaking sectors

\begin{tabular}{|c|c|c|c|c|c|c|c|c|c|c|c|}
\hline \multirow{2}{*}{ Sector } & \multirow{2}{*}{ Year } & \multirow{2}{*}{$\begin{array}{c}\text { Total } \\
\text { Incidents }\end{array}$} & \multirow{2}{*}{$\begin{array}{c}\text { LTI } \\
0 \text { day } \\
\text { away } \\
\text { from } \\
\text { work }\end{array}$} & \multirow{2}{*}{$\begin{array}{l}\text { LTI } \\
1 \text { to } 5 \\
\text { days } \\
\text { away } \\
\text { from } \\
\text { work }\end{array}$} & \multirow{2}{*}{$\begin{array}{c}\text { LTI } \\
\text { More } \\
\text { than } 5 \\
\text { days } \\
\text { away } \\
\text { from } \\
\text { work }\end{array}$} & \multirow{2}{*}{$\begin{array}{l}\text { Work- } \\
\text { related } \\
\text { traumatic } \\
\text { injury/ } \\
\text { fatalities }\end{array}$} & \multicolumn{4}{|c|}{ Direct Cost (\$) } & \multirow[t]{2}{*}{$\begin{array}{c}\text { Total } \\
\text { Direct } \\
\text { Cost }(\$) \\
\end{array}$} \\
\hline & & & & & & & $\begin{array}{l}\text { Minor } \\
\text { Injury }\end{array}$ & $\begin{array}{l}\text { Severe } \\
\text { Injury }\end{array}$ & $\begin{array}{l}\text { Permanent } \\
\text { Disability }\end{array}$ & Death & \\
\hline \multirow{3}{*}{ RMG } & 2016 & 153 & 26 & 28 & 99 & 6 & 2028 & 30632 & 154737 & 7500 & 194897 \\
\hline & 2017 & 144 & 54 & 70 & 20 & 16 & 4212 & 76580 & 31260 & 20000 & 132052 \\
\hline & 2018 & 12 & 6 & 3 & 3 & 1 & 468 & 3282 & 4689 & 1250 & 9689 \\
\hline \multirow{3}{*}{ Textile } & 2016 & 58 & 10 & 27 & 21 & 8 & 780 & 29538 & 32823 & 10000 & 73141 \\
\hline & 2017 & 254 & 140 & 114 & 0 & 13 & 10920 & 124716 & 0 & 16250 & 151886 \\
\hline & 2018 & 9 & 7 & 2 & 0 & 0 & 546 & 2188 & 0 & 0 & 2734 \\
\hline \multirow{3}{*}{$\begin{array}{l}\text { Ship } \\
\text { Breaking }\end{array}$} & 2016 & 14 & 0 & 5 & 6 & 3 & 0 & 5470 & 9378 & 3750 & 18598 \\
\hline & 2017 & 21 & 0 & 6 & 8 & 7 & 0 & 6564 & 12504 & 8750 & 27818 \\
\hline & 2018 & 11 & 0 & 0 & 0 & 11 & 0 & 0 & 0 & 13750 & 13750 \\
\hline
\end{tabular}

It was observed that the highest economic loss occurred mostly in RMG and Textile sectors during the analysis period.

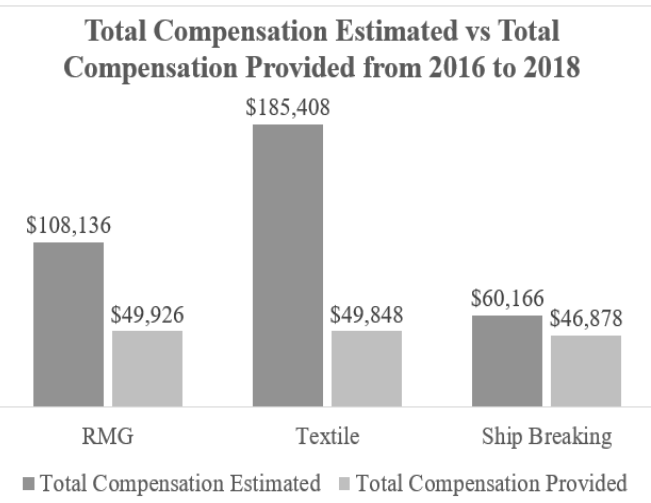

Fig. 5: Total compensation estimated vs provided to the dead and injured workers in RMG, Textile and Ship Breaking sectors from 2016 to 2018 according to the data from DIFE

According to the data from DIFE, in Fig. 5, it was found that the total compensation provided to the workers for workplace injuries and fatalities was less than our estimated costs. The reason behind this difference may be the unwillingness of the factory owners to bear this additional expense.

\section{$5 \quad$ Results and Discussion}

This study represented the first attempt to estimate the costs of occupational injuries in RMG, Textile and Ship Breaking sectors. In this work, the - direct costs such as administrative and legal costs and indirect costs such as loss of productivity and healthrelated quality of life (pain/suffering/ psychological problems) were not estimated.

For the comparison of RMG, Textile and Ship Breaking industry, the entire numbers of occurrences under different category for all three years were analysed, from which the ultimate percentages of the occurrences are represented in the Fig. 6 below.

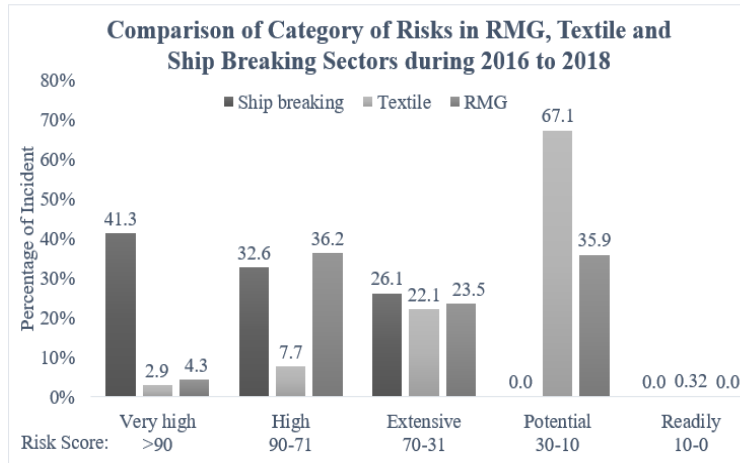

Fig. 6: Comparison of various risk categories for three different industries

From Fig. 6, it is seen that the percentages of potentially risky incident are highest in textile and garments sector and almost no incident found in readily risk category. About $25 \%$ incidents in each sector occurred under extensive risk category. Similarly, about 35\% incident of Ship Breaking, and garments sector occurred under high-risk category, but the percentages were lowered to $8 \%$ for textile sector. About $42 \%$ of very high risky incidents can be 
observed in Ship Breaking industry while incidents in textile and RMG sector were below $5 \%$.

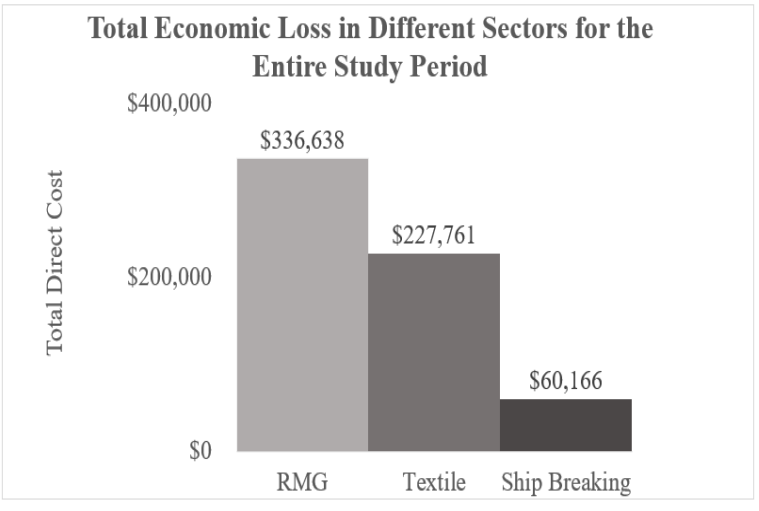

Fig. 7: Comparison of total economic loss for three different Industries

Total direct costs for the entire analysis period were found by summing annually calculated direct cost and graphically represented in

Fig. 7. For the study period of consecutive three years (2016, 2017 and 2018), total direct cost in RMG sector was the highest followed by textile and Ship Breaking industry.

Devastating fire incidents were intense in RMG sector which led to increase the number of hazardous incidents far higher than the textile and shipbreaking industry.

The result presented in this paper is based on the data reported to DIFE, which may underrepresent the real scenario at the factories, as the factory owners and the concerned personnel may report lower casualty numbers for the reputation of the factory and the associated compensation.

In Bangladesh, the occupational safety of different industries is mainly affected by poor maintenance, operational system, less awareness and motivation for adherence to legal requirements and unemployed poverty-stricken population [6], which is well reflected in the survey data and calculated risk scores

\section{Conclusion and Recommendation}

An approach for determining risk score in RMG, Textile and Ship Breaking industries was presented in this paper with associated economic loss of occupational injuries and fatalities.

1. The empirical study has extracted an overall scenario of these factories in Bangladesh in the context of occupational safety and health condition.

2. In Ship Breaking sector, $41.3 \%$ of total incidents are of very high-risk category where RMG and Textile sectors include a lower percentage of high-risk incidents.
3. It is also found in this study that fire incidents in RMG and Textile sectors are very common and causing colossal damage of lives and properties.

4. Total economic loss based on injuries and fatalities in RMG, Textile and Ship Breaking sectors from 2016 to 2018, as per data, is 624565 USD.

5. The total compensation provided to the workers based on their death and type of injuries is 58.5\% less than estimated cost. This indicates the negligence of factory owners regarding workers' rights.

The methodology used in this study may be replicated for the purposes of determining the risk score and estimating the costs of injuries and fatalities in other sectors.

\section{References}

[1] K. Straif, "32nd Triennial Congress of the International Commission on Occupational Health, ICOH," Occup. Environ. Med., vol. 75, no. Supplement 2, pp. 1-651, 2018.

[2] "ISO 31000:2018(en), Risk management Guidelines.".

[3] C. J. Badenhorst, "Occupational Health Risk Assessment: Central to the management of occupational health," in International Platinum Conference 'Platinum Adding Value,' 2004, pp. 4752.

[4] Afrooz Moatari Kazerouni \& Bruno Agard; Yuvin Chinniah, "A proposed occupational health and safety risk estimation tool for manufacturing systems," Int. J. Prod. Res., vol. 53, no. 15, pp. 4459-4475, 2014.

[5] "Problems of Garments Industry in Bangladesh Assignment Point." https://www.assignmentpoint.com/science/textile/pro blems-garments-industry-bangladesh.html (accessed May 08, 2021).

[6] Fabiha Tasnim, "A Review on Occupational Health Safety in Bangladesh with Respect to Asian Continent," Int J Pub Heal. safe Int. J. Public Heal. Saf., vol. 1, no. 1, pp. 1-9, 2016.

[7] M. . A. U. Bhuiyan, "RMG Sector Risk Management and Social Compliances in Bangladesh," Dhaka, 2018.

[8] "BTMA - Bangladesh Textile Mills Association." https://www.btmadhaka.com/ (accessed Jun. 14, 2020).

[9] "Norway issues $\$ 767,000$ fine on shipping company for illegal scrapping - SAFETY4SEA."

[10] G. of Bangladesh, Bangladesh Labour Law, 2006. Dhaka: Ministry of Labour and Employment, 2006.

[11] Bangladesh Bureau of Statistics, "Report on Economic Census 2013,” Dhaka, 2015. 
[12] "Department of Inspection for Factories and Establishments-Ministry of Labour and Employment." http://dife.portal. gov.bd/site/page/ 51db0606-47a3-4d10-b4e3-2e6e7a33d893 (accessed Jun. 14, 2020).

[13] R. K. Saha, M. S. Islam, and M. M. Rahman, "Safety management for Bangladeshi shipbreaking industries perspective," Glob. J. Res. Eng., vol. 13, no. 5, pp. 22-27, 2013
[14] ISO/TC 199 Safety of machinery, "ISO 12100:2010Safety of Machinery - General Principles for Design - Risk Assessment and Risk Reduction," Int. Organ. Stand. Geneva, Switz., vol. 2010, p. 77, 2010.

CB Bangladesh Uni. of Engg. \& Tech. 